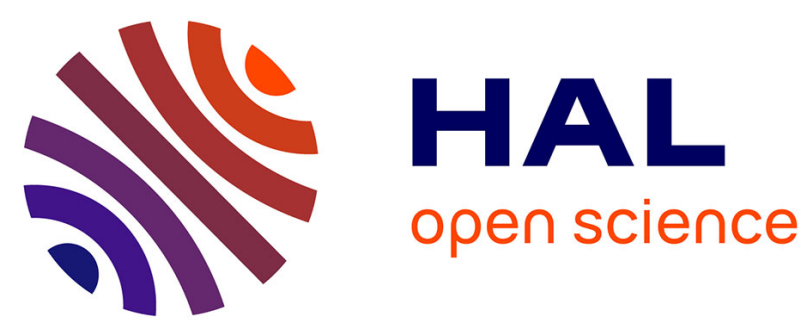

\title{
Reinforced silica monoliths functionalised with metal hexacyanoferrates for cesium decontamination: a combination of a one-pot procedure and skeleton calcination
}

A Sommer-Marquez, C Mansas, N Talha, Cyrielle Rey, Jérémy Causse

\section{To cite this version:}

A Sommer-Marquez, C Mansas, N Talha, Cyrielle Rey, Jérémy Causse. Reinforced silica monoliths functionalised with metal hexacyanoferrates for cesium decontamination: a combination of a one-pot procedure and skeleton calcination. RSC Advances, 2016, 6 (77), pp.73475 - 73484 . 10.1039/c6ra16980e . hal-03202594

\section{HAL Id: hal-03202594 \\ https://hal.science/hal-03202594}

Submitted on 20 Apr 2021

HAL is a multi-disciplinary open access archive for the deposit and dissemination of scientific research documents, whether they are published or not. The documents may come from teaching and research institutions in France or abroad, or from public or private research centers.
L'archive ouverte pluridisciplinaire HAL, est destinée au dépôt et à la diffusion de documents scientifiques de niveau recherche, publiés ou non, émanant des établissements d'enseignement et de recherche français ou étrangers, des laboratoires publics ou privés. 


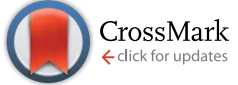

Cite this: RSC Adv., 2016, 6, 73475
Received 1st July 2016

Accepted 18th July 2016

DOI: 10.1039/c6ra16980e

www.rsc.org/advances

\title{
Reinforced silica monoliths functionalised with metal hexacyanoferrates for cesium decontamination: a combination of a one-pot procedure and skeleton calcination $\dagger$
}

\author{
A. Sommer-Marquez, C. Mansas, N. Talha, C. Rey and J. Causse*
}

\begin{abstract}
The nuclear plant accident of Fukushima Daiichi occurred following a tsunami on March 11th 2011 and gave rise to the production of large volume aqueous outflows containing radioactive cesium and seawater. This problem urged researchers to develop materials suitable for high flux continuous sorption processes able to promote the selective entrapment of cesium while sodium is widely present in the contaminated outflows. This work is focused on the achievement of silica monoliths with hierarchical porosity (meso- and macropores) combining on one hand enhanced mechanical strength thanks to a calcination step and on the other hand a one-pot functionalisation procedure in order to insert metal hexacyanoferrate (MHCF) particles inside the pores. This combination is generally difficult to achieve due to the MHCF alteration for temperatures above $200{ }^{\circ} \mathrm{C}$. However, these problems can be avoided following the procedure described in this paper. Finally synthetic routes for meso/macroporous silica monoliths functionalised with sorbent particles highly selective towards cesium, CoHCF, CuHCF and ZnHCF are described. The weight ratio of MHCF reaches $7.1 \%$ wt with a total cesium sorption capacity of $24.1 \mathrm{mg} \mathrm{g}^{-1}$ in the case of monoliths functionalised with $\mathrm{ZnHCF}$. This value is not altered by the presence of sodium in the aqueous solution. MHCF particles are located mainly inside the macropores while the mesopore network allows for a high exchange surface between the aqueous outflows and MHCF particles embedded in the monoliths.
\end{abstract}

\section{Introduction}

The problem of water contamination due to the Fukushima nuclear plant accident following the tsunami which occurred on March, 11th 2011 makes ${ }^{137} \mathrm{Cs}$ extraction a topical issue. Research programs developed in recent years have given rise to many different kinds of materials designed to remove Cs from aqueous outflows. Both chemical nature and selectivity towards Cs with regard to other alkaline competitive ions such as Na are the most relevant properties of these materials. This is particularly true in the case of Fukushima Daiichi because of the presence of seawater in the outflows, containing large amounts of sodium. From a chemical nature point of view, materials should also be designed assuming the fact that they will be finally incorporated into parcels made of glass or concrete for longtime disposal. Therefore, they have to be compatible with these matrices.

Institut de Chimie Séparative de Marcoule ICSM, UMR 5257, CNRS/CEA/UM/ENSCM, BP 17171, 30207 Bagnols sur Cèze, France. E-mail: jeremy.causse@cea.fr

$\dagger$ Electronic supplementary information (ESI) available: Detailed experimental procedures, XRD and FT-IR data. See DOI: 10.1039/c6ra16980e
Bulk as well as composite materials can be used for Cs removal. Generally composite materials are made of a support functionalised with sorbent particles or nanoparticles allowing enhancement of the materials performance. For example, by using sorbent nanoparticles instead of bulk, the specific surface available for the sorption is higher. Similarly, the use of a porous support in a composite material is also beneficial and generally increases the sorption kinetics. However, the chemical nature of the support should be chosen in order to be compatible with nuclear waste confinement parcels. While organic supports have been studied exhibiting quite good Cs sorption performances, ${ }^{1-3}$ inorganic supports such as silica ${ }^{4}$ are really more adapted for a dispersion inside glass or cement matrices due to their better resistance to radiation damage.

Various kinds of sorbents have been used in the past either under bulk form or grafted nanoparticles for inorganic sorbents and grafted molecules for organic ligands. Bentonite, ${ }^{5,6}$ montmorillonite, ${ }^{7}$ titanate, ${ }^{8}$ zirconia, ${ }^{9}$ crown-ether molecules ${ }^{10-12}$ or chalcogenides ${ }^{13-16}$ can be mentioned, whose efficiency and selectivity towards Cs however do not reach similar performances to the well-known Prussian Blue Analogue (PBA) family compounds $^{17-31}$ (or metal hexacyanoferrate, MHCF, Fig. 1). These coordination polymers have been studied for the first 


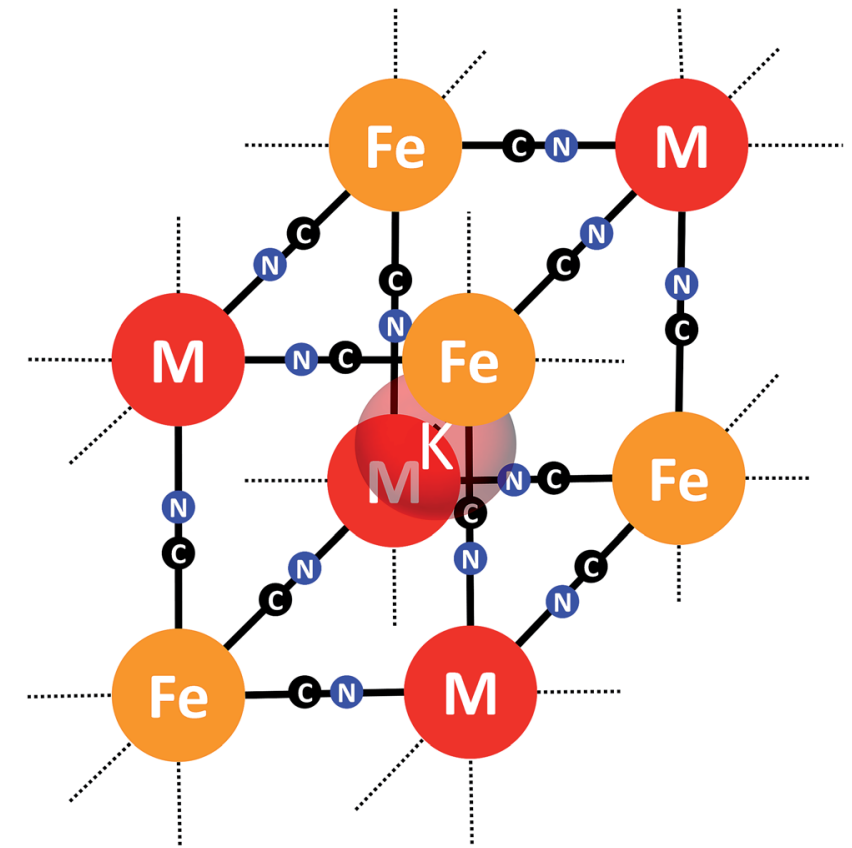

Fig. 1 Schematic view of the PBA structures used in this work. The general formula is $\mathrm{K}_{x} \mathrm{M}_{y}^{\prime \prime}\left[\mathrm{Fe}^{\prime \prime}(\mathrm{CN})_{6}\right]_{z}$.

time for their magnetic properties, ${ }^{32}$ but the high-selectivity towards Cs they provide makes them the first choice in the case of nuclear decontamination of radioactive Cs. These compounds are made of transition metal atoms linked to iron atoms via a bridged cyano group. ${ }^{33,34}$

When a transition metal $M$ at oxidation state (II) is used for the PBA elaboration as well as Fe(II), alkali ions can be incorporated in the center of the lattice. This alkali ion allows the compound to be electronically neutral and is not covalently bonded to the structure. This alkali element is therefore exchangeable with cesium with a huge selectivity towards Cs ions. For example, in the case of outflows containing much more $\mathrm{Na}\left(0.5 \mathrm{~mol} \mathrm{~L}^{-1}\right)$ than ${ }^{137} \mathrm{Cs}\left(1 \times 10^{-11} \mathrm{~mol} \mathrm{~L}^{-1}\right)$, CuHCF have been found to still uptake Cs with $K_{\mathrm{d}}$ up to $1 \times 10^{5} \mathrm{~mL} \mathrm{~g}^{-1}$ for materials containing only $5.1 \%$ wt of CuHCF. ${ }^{35}$ MHCF can be used either under bulk form ${ }^{36}$ or covalently grafted ${ }^{37,38}$ on the surface of a support or immobilized inside a porous support. ${ }^{35}$

From a process point of view, a porous support, and more particularly materials with hierarchical porosity are very promising. In fact, mesoporosity and macroporosity can both bring some crucial properties for the development of the industrial process. Indeed, mesopores (between $2 \mathrm{~nm}$ and $50 \mathrm{~nm}$ ) generally promote a high specific surface and therefore a high exchange surface in the case of a sorbent immobilized/grafted in the support. On the other hand, macroporosity (>50 $\mathrm{nm}$ ) allows for a high flux treatment by limiting pressure drops when the liquid passes through the composite material. The presence of pores at different length scales in the support is therefore a property taken into account in the design of the materials presented in this paper.

The shaping of an inorganic support into a macroporous monolithic form allows its compatibility with a continuous process. Recent studies have shown different ways to synthesize silica monoliths using simple methods. While Nakanishi et al. used phase separation of a hydrophilic polymer during the solgel process to promote microdomains as macropores, ${ }^{39,40}$ Backov et al. ${ }^{41}$ and Binks et al. ${ }^{42}$ used oil drops in emulsions to promote these macropores. The method developed by Backov et al. used a molecular surfactant to stabilize a direct oil-inwater high-internal phase emulsion. The oil drops are then used as a template during the sol-gel process to promote macropores while surfactant micelles are used as a template to promote mesopores after either a thermal or a washing treatment to remove the surfactant molecules. This synthesis route presents some advantages like, for example, the possibility of using a colloidal suspension as the water phase to develop a one-pot procedure. In this case, the colloids are made of MHCF for example. ${ }^{35}$ After the sol-gel process, the monolith is therefore functionalised, due to the fact that MHCF nanoparticles were already present in the water phase of the emulsion. This procedure allows the avoidance of any postfunctionalisation step and therefore the use of a non-green solvent, such as toluene. However, PBAs are sensitive to temperature and they cannot be treated with a temperature higher than $200{ }^{\circ} \mathrm{C}$ without altering the PBA microstructure. Therefore, the monoliths prepared following this procedure cannot be calcined, affecting the mechanical strength of the materials. The work presented in this paper shows a new onepot synthesis route where calcination of the substrate is possible.

\section{Results and discussion}

\section{"Nearly one-pot" procedure}

The synthesis route presented in this paper allows the insertion of a wide range of PBA particles without being dependent on a post-functionalisation step and therefore on the silanol group density located at the surface of the monolith. That is why this procedure can be defined as a "nearly one-pot" procedure. The main advantage of this new procedure is the possibility to consider calcination of the monolith, contrary to the case of the first "one-pot" procedure described in the literature. In fact, the water phase used to prepare the emulsion already contains transition metal ions. After the addition of a molecular surfactant, namely Pluronic P123, and of a silica source, basically tetraethyl orthosilicate (TEOS), emulsification of cyclohexane is performed with an Ultra-Turrax device. At this point, the oil-inwater $(\mathrm{O} / \mathrm{W})$ emulsion is done, made of cyclohexane oil drops stabilized by the surfactant, and with metallic cations in the water phase in close vicinity to the surfactant ${ }^{43}$ (Fig. 2, left).

Then, a sol-gel process is performed to make the silica network grow in the water phase of the emulsion. Finally, after several days, a silica monolith full of cyclohexane is obtained. Then, the macropores are emptied by leaving the monoliths at room temperature in order to slowly evaporate the cyclohexane. The calcination step at $500{ }^{\circ} \mathrm{C}$ increases the mechanical strength of the silica skeleton and also gives rise to mesopores due to surfactant templating (Fig. 2, right). 

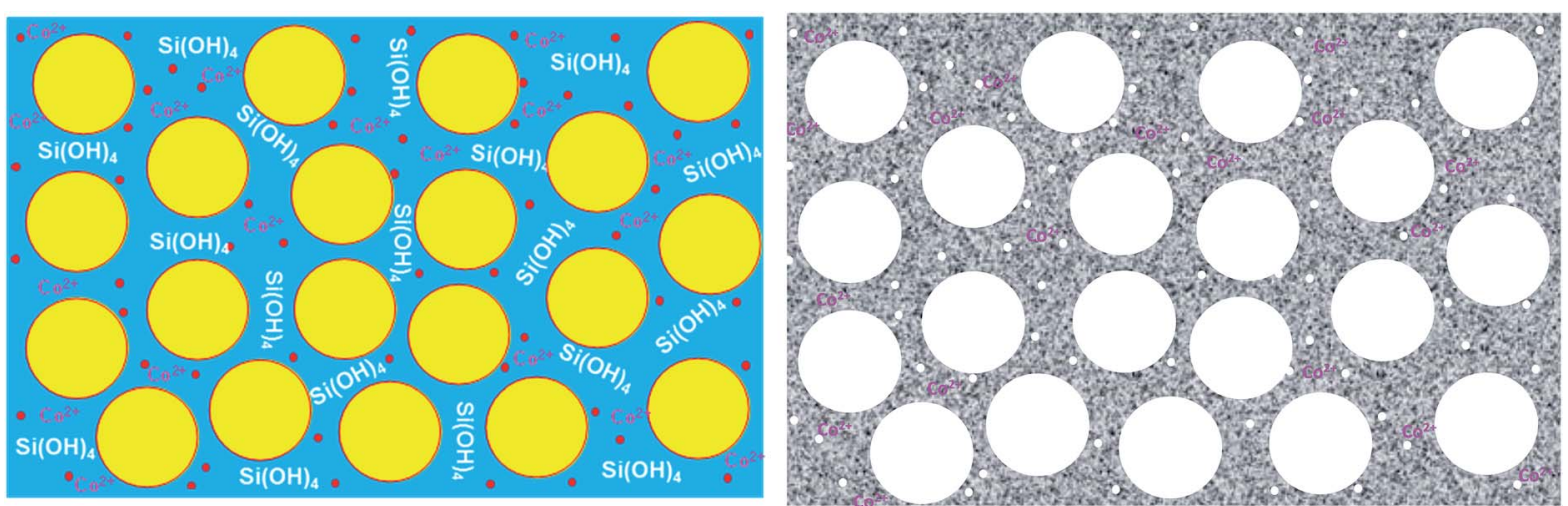

Fig. 2 Schematic representation of the high-internal phase emulsion (HIPE) used as a template for the monolithic material (left), and of the material itself after the calcination steps. In this example, the metallic cation used is cobalt but this can be extended to Cu or Zn. P123 is represented in red.

Then, growth of the PBA particles is performed using a simple impregnation step with an acidic aqueous solution of $\mathrm{K}_{4} \mathrm{Fe}(\mathrm{CN})_{6}$. The transition metal species already present in the silica monolith act as nucleation points. Fig. 3 shows both the calcined and impregnated monoliths. Typical colors of copper (CuHCF), zinc (ZnHCF) and cobalt hexacyanoferrate (CoHCF), respectively red, yellow and dark purple are observed. The change in color after the impregnation step is due to the coordination of transition metal atoms to the hexacyanoferrate complex.

\section{Microstructure}

Fig. 4 shows the XRD data for bulk $\mathrm{CoHCF}$ and the silica monoliths functionalised with ZnHCF, CoHCF and CuHCF. The bulk compounds as well as the CuHCF and CoHCF monoliths present pure face-centered cubic lattices while the ZnHCF monoliths present a mix of rhombohedral and cubic lattices. This behaviour is known in the case of $\mathrm{Zn}$ based compounds, where rhombohedral structures are favored, ${ }^{34,44}$ even in the case of the bulk compound in this study (see ESI†). Bulk CoHCF presents a classical cubic structure where potassium atoms are integrated inside the lattice with the following stoichiometry $\mathrm{K}_{2} \mathrm{Co}\left[\mathrm{Fe}^{\mathrm{II}}(\mathrm{CN})_{6}\right]$ (pdf no. 01-075-0038). MHCF immobilised inside each kind of monolith also presents this typical structure $\left(\mathrm{K}_{2} \mathrm{Cu}\left[\mathrm{Fe}^{\mathrm{II}}(\mathrm{CN})_{6}\right]\right.$, pdf no. 01-075-0023 or $\mathrm{KCu}\left[\mathrm{Fe}^{\mathrm{III}}(\mathrm{CN})_{6}\right]$, pdf no.

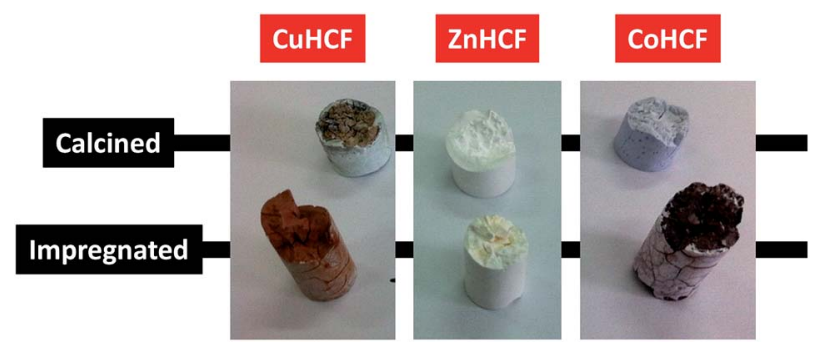

Fig. 3 Both calcined and impregnated silica monoliths prepared via emulsion templating. Functionalisation is achieved with copper, zinc and cobalt hexacyanoferrate respectively from left to right.
01-070-6402; and $\mathrm{Zn}_{3}\left[\mathrm{Fe}^{\mathrm{III}}(\mathrm{CN})_{6}\right]_{2}$, pdf no. 00-038-0687), with the presence of rhombohedral $\mathrm{K}_{2} \mathrm{Zn}_{3}\left[\mathrm{Fe}^{\mathrm{II}}(\mathrm{CN})_{6}\right]_{2}$ in the case of ZnHCF (pdf no. 00-033-1061).

It is therefore well established that MHCF structures are present in the silica monoliths with, for the most part, a cubic centered face lattice, and a supplementary rhombohedric one in the case of ZnHCF. In some cases oxidation of HCF from the +II state to +III can be observed. It is confirmed using FT-IR experiments, especially in the case of CuHCF and ZnHCF where a supplementary band corresponding to $-\mathrm{Fe}^{\mathrm{III}}-\mathrm{CN}-$ is observed in the range $2150-2200 \mathrm{~cm}^{-1}$. This could be due to the acidic medium of the $\mathrm{K}_{4}\left[\mathrm{Fe}(\mathrm{CN})_{6}\right]$ solution used for the growth of the MHCF particles during the impregnation step.

SEM-EDX and X-ray fluorescence measurements were also used to assess the MHCF concentrations in each of the silica monoliths exhibiting a loading rate of about $7 \%$ wt. SEM images are presented in Fig. 5. They show classical morphologies for this kind of monolith. The macropores are interconnected

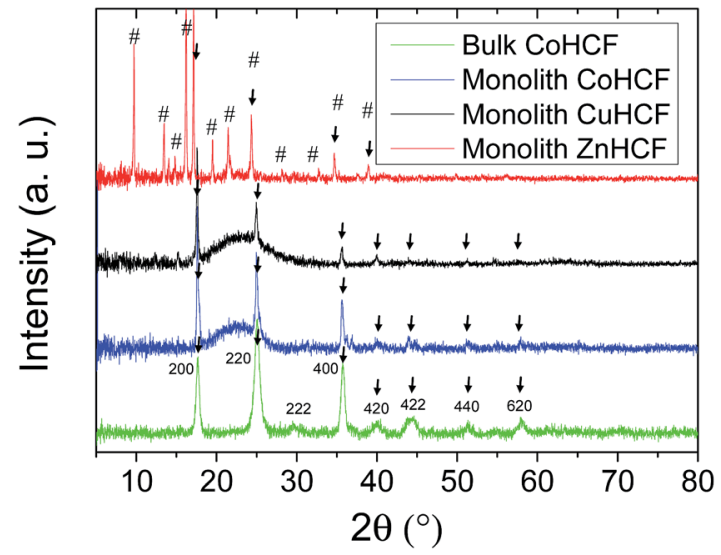

Fig. 4 XRD data for bulk CoHCF and for the silica monoliths functionalised with CuHCF, ZnHCF and CoHCF. Reflections relative to the cubic structures are represented with an arrow. Lattice planes are indicated on the CoHCF bulk diffractogram. Reflections relative to a rhombohedral structure are represented with \#. Diffractograms are shifted in the $Y$-axis for a better readability of the figure. 

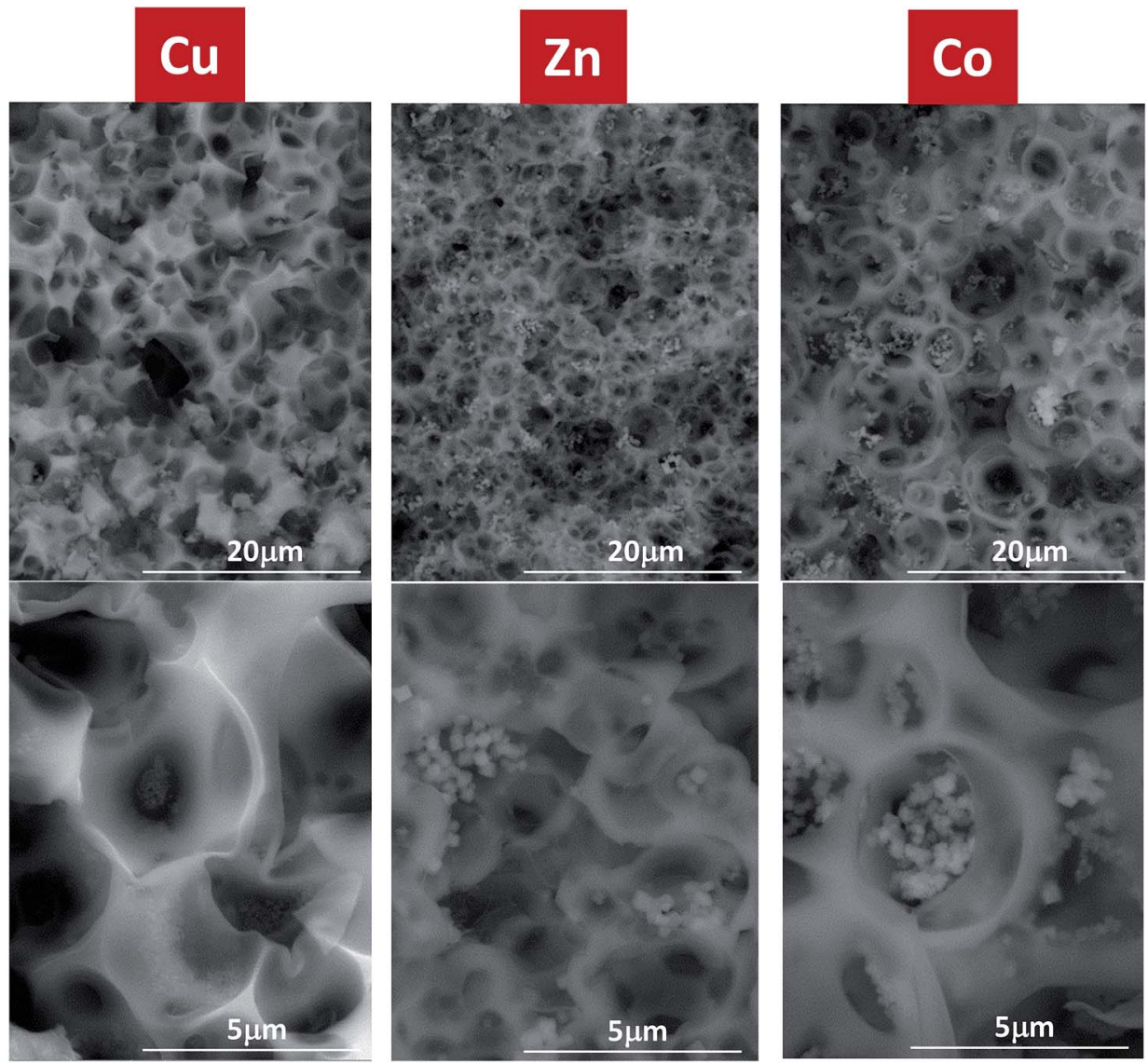

Fig. 5 SEM pictures of the monoliths functionalised with CuHCF, ZnHCF and CoHCF at two different focuses (2500x and 10 000 $\times$ ).

spheres whose shape is due to the presence of oil drops in the emulsion used to prepare the materials. The lowest focus allows determination of the macropore mean radius for each system.

This has been done using a numerical measurement with a macropore count number of at least 50 . The macropore mean size is $4.2 \mu \mathrm{m}, 4.1 \mu \mathrm{m}$ and $2.3 \mu \mathrm{m}$ for monoliths functionalised with respectively, CuHCF, CoHCF and ZnHCF. The lowest macropore size obtained for the ZnHCF system can be explained by a salting-out effect due to the presence of salts in the water phase of the emulsion. Indeed, it is known that inorganic salts can induce polyethylene oxide (PEO) chain dehydration. ${ }^{45,46}$ This tends to make the PEO based surfactant more hydrophobic. Consequently, there are more surfactant molecules stabilizing the oil drops and finally, the oil drop size is decreased. This behaviour is more pronounced in the case of $\mathrm{Zn}^{2+}$ salts explaining why the order of magnitude of the macropore size is lower.

Fig. 5 also shows the presence of MHCF particles in the inner part of the macropores (focus $10000 \times$ ). The cubic shape of these particles is expected and the size changes depending on the nature of the metal considered. It ranges from approximately $50-150 \mathrm{~nm}$ in the case of CuHCF, to $300-500 \mathrm{~nm}$ in the case of ZnHCF and CoHCF. The copper hexacyanoferrate therefore exhibits a smaller size of particles. This behaviour has already been noticed in past studies where stable colloidal suspensions of CuHCF were easier to prepare than with other metals. $^{35}$

\section{Mesoporous network}

As previously explained, the monolith porosity is hierarchical. There are not only macropores but also mesopores, due to the presence of surfactants in the water phase of the emulsion (Fig. 6). Gas adsorption measurements have been undertaken in order to assess the nature of the porosity and the specific surface for each kind of monolith. These parameters are directly linked to the presence of mesopores or micropores in the materials. All the isotherms presented in Fig. 7 are type IV isotherms characteristic of mesoporous materials because of the presence of a hysteresis loop.

It is also clear that porous volume as well as specific surface is lowered after the impregnation step of the monoliths done in order to make the MHCF particles grow. These values are listed in Table 1.

This loss of $S_{\mathrm{BET}}$ and $V_{\mathrm{P}}$ is a sign that the mesopores are either filled, just like in the work of Fornasieri, ${ }^{47}$ or obstructed by the MHCF particles. TEM images presented in Fig. 6 show empty mesopores for all the studied materials. This tends to show that the precipitation of MHCF during the impregnation step is limited to the silica surface inside the macropores. 

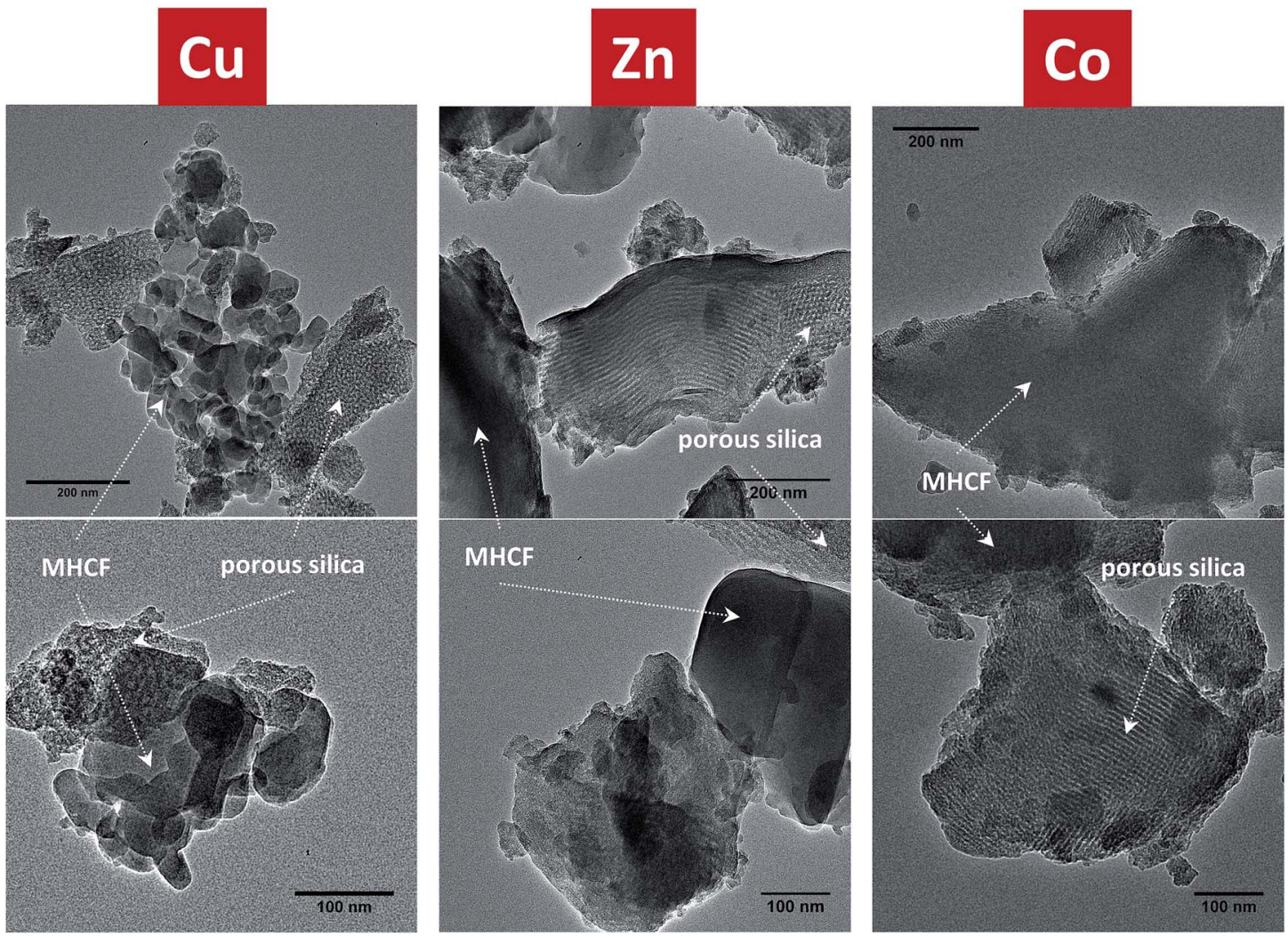

Fig. 6 TEM images of the silica monoliths functionalised with CuHCF, ZnHCF and CoHCF.

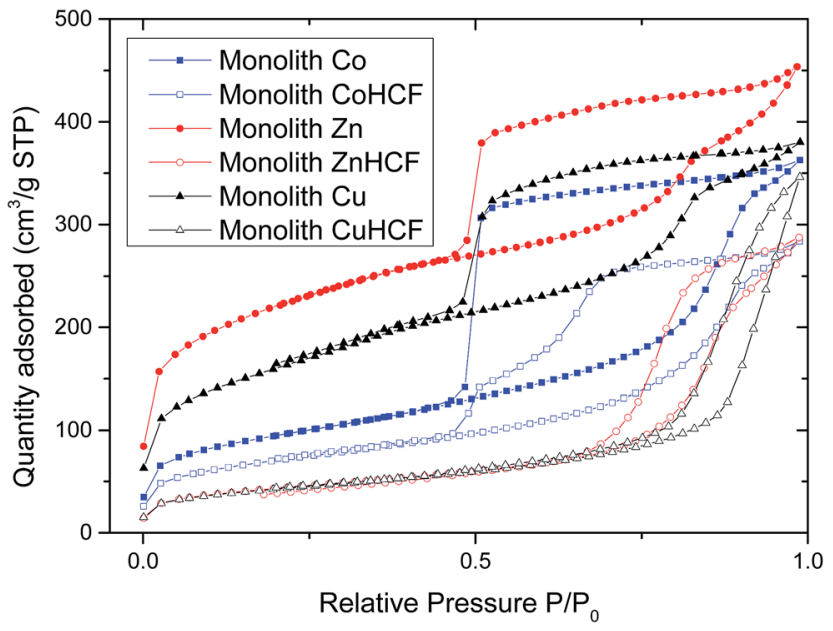

Fig. $7 \mathrm{~N}_{2}$ adsorption-desorption measurements for the silica monoliths functionalised with CoHCF, ZnHCF and CuHCF. Comparison with the corresponding materials before the $\mathrm{K}_{4}[\mathrm{Fe}(\mathrm{CN})]_{6}$ impregnation step (monoliths with only transition metal dispersed within the skeleton).

The fact that no MHCF is present inside the mesopores could be explained by the use of a templated emulsion. Indeed, the surfactant micelles remaining in the aqueous phase of the emulsion are also filled by a part of the oil phase. The oil phase is actually divided in the oil drops, for most of it, but also in the surfactant micelles. The presence of this oil part in the micelle therefore blocks the access of it to the hydrophilic metallic cation. The consequence is the absence of a nucleation point for the growth of the MHCF particles in the surfactant micelles and therefore neither in the mesopore. This behaviour can explain why the mesopores are free of MHCF contrary to the case of the Fornasieri et $a .^{47}$ article where no emulsion is used to prepare a non-macroporous material.

Fig. 6 also gives information about the arrangement of the mesopores network. For monoliths functionalised with CoHCF and ZnHCF, the mesopore network presents some organised parts following a hexagonal array while the materials containing CuHCF do not exhibit any sign of organisation.

This tendency is confirmed using the SAXS measurements presented in Fig. 8. This technique allows the characterisation and identification of the crystalline arrangement at a large scale $(>1 \mathrm{~nm})$ with a simple indexation of the Bragg reflections. For example, the Bragg peaks relative positions of the hexagonal compact array are given at $1 ; \sqrt{ } 3 ; 2 ; \sqrt{ } 7$.. Monoliths functionalised with CoHCF and ZnHCF exhibit SAXS curves with three characteristic first order peaks. These peaks are broadened because the homogeneity of the sample is not perfect, from a crystalline arrangement of the mesopore network point of view. This means that some parts of the silica skeleton of the monoliths present a perfectly organised mesopore network while some other parts do not. While TEM shows local information, SAXS characterisations are more general and take into account a much bigger part of the sample. 
Table 1 MHCF content, specific surface $S_{B E T}$ and porous volume $V_{P}$ of each monolith prepared in this work

\begin{tabular}{|c|c|c|c|c|c|}
\hline & \multirow{2}{*}{$\begin{array}{l}\% \\
\text { wt MHCF }\end{array}$} & \multicolumn{2}{|l|}{$S_{\text {BET }}\left(\mathrm{m}^{2} \mathrm{~g}^{-1}\right)$} & \multicolumn{2}{|l|}{$V_{\mathrm{P}}\left(\mathrm{cm}^{3} \mathrm{~g}^{-1}\right)$} \\
\hline & & Before impr. & Impregnated & Before impr. & Impregnated \\
\hline Monolith CuHCF & 6.9 & 559 & 150 & 0.58 & 0.53 \\
\hline Monolith ZnHCF & 7.4 & 571 & 152 & 0.53 & 0.44 \\
\hline
\end{tabular}

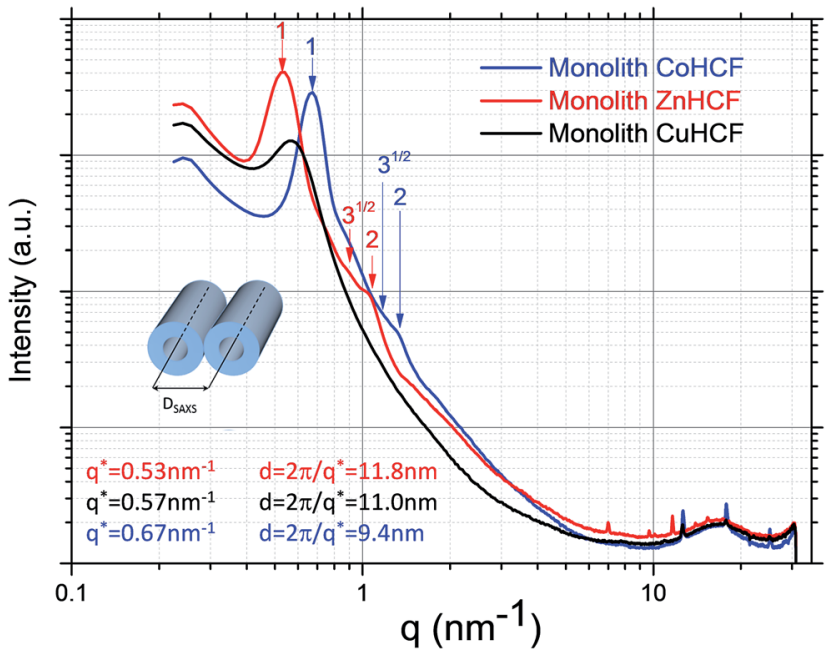

Fig. 8 SAXS measurements on the silica monoliths functionalised with CUHCF, ZnHCF and CoHCF.

SAXS data give information about the local organisation of the samples at a given length scale that is only dependent on the $q$ range. For example, at high $q$ values, interatomic distances are relevant. That is the reason why the diffraction peaks of MHCF are visible from $q=7 \mathrm{~nm}^{-1}$. For high $q$ values, there is therefore a recovery between SAXS and XRD measurements.

On the other hand long distances (several nanometers) are investigated at low $q$ values. This part of the curves therefore gives information about the mesopores arrangement. While it is possible to know if mesopores exist following a well-ordered crystal structure, the simple use of the structure factor (1st order peak) allows the calculation of the mean distance between two pore centers (see diagram on Fig. 8). The value of $q^{*}$ is directly related to this distance $d$ with the following relation $d=$ $2 \pi / q^{*}$. This parameter $d$ is equal to the addition of a pore diameter with the silica skeleton wall thickness. The values calculated with SAXS data are consistent with the TEM images shown in Fig. 6. The order of magnitude of this parameter is similar to what has previously been found with SBA-15 powders which are prepared with the same surfactant, Pluronic P123. ${ }^{48,49}$

\section{Cesium sorption}

Sorption efficiency was measured to assess the functionalised monoliths performance towards cesium uptake. First, experiments were led with bulk MHCF in order to achieve reference sorption measurements. The results are presented in Fig. 9 (upper part for bulk compounds). The experimental points are fitted with a Langmuir model:

$$
Q=Q_{\mathrm{MAX}} K_{\mathrm{L}} \frac{C_{\mathrm{eq}}}{1+K_{\mathrm{L}} C_{\mathrm{eq}}}
$$

where $Q$ is the quantity of cesium uptaken in the materials for a given equilibrium concentration $C_{\mathrm{eq}}$ in the solution. $Q_{\mathrm{MAX}}$ and $K_{\mathrm{L}}$ are fit parameters respectively corresponding to the sorption capacity of the materials and to the Langmuir constant whose values give information about the selectivity of the solids
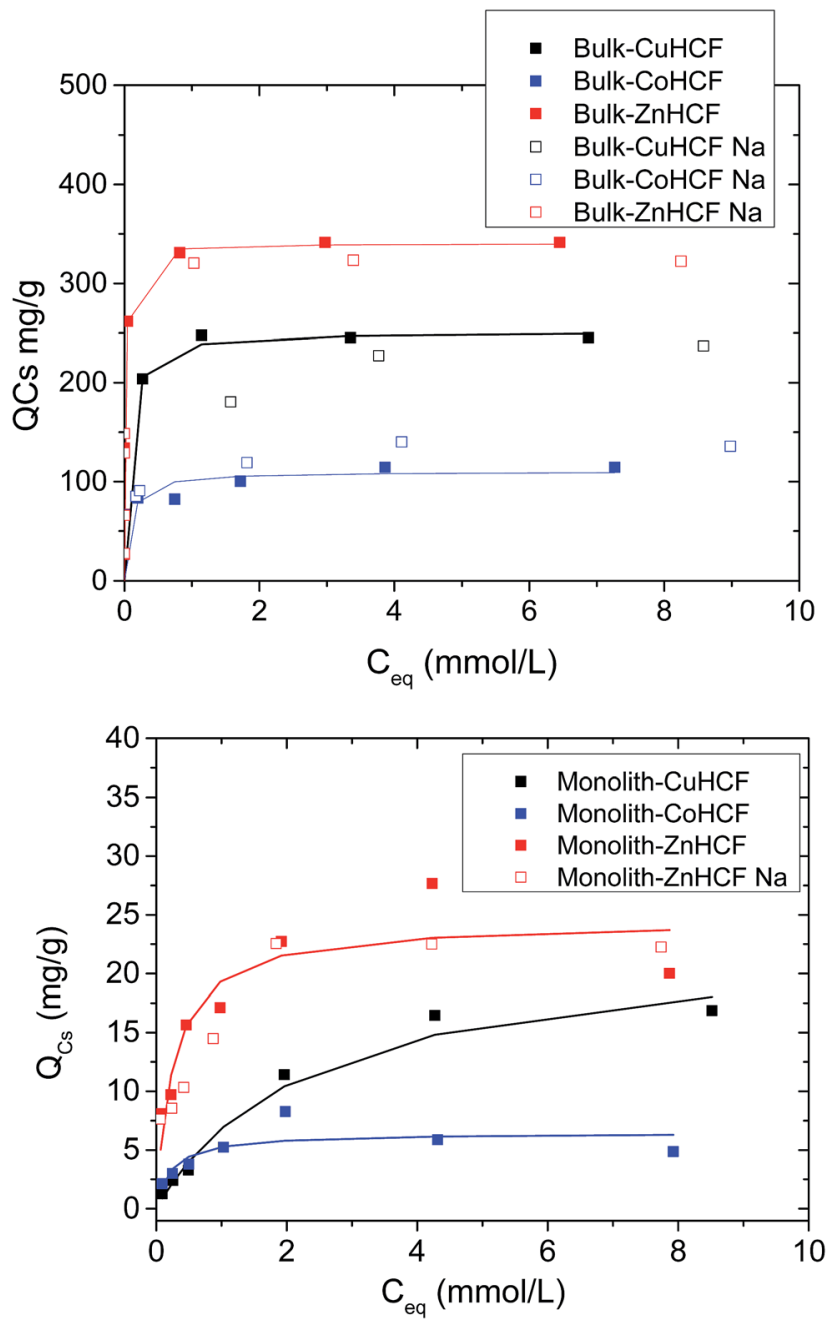

Fig. 9 Cs sorption isotherms relative to bulk MHCF materials as well as the monoliths. 
Table 2 Langmuir equation fit parameters, $Q_{\operatorname{MAX}}$ and $K_{\mathrm{L}}$ for all materials studied

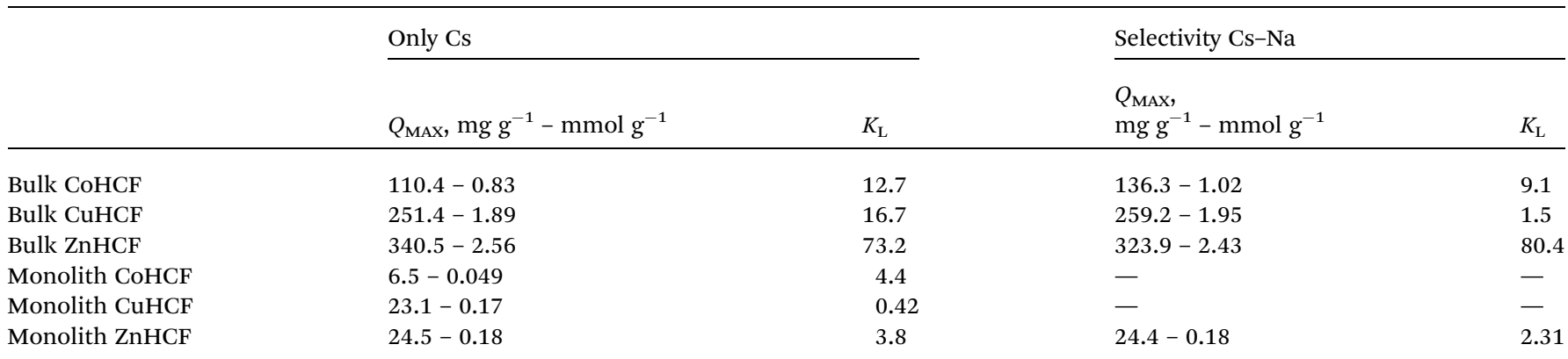

towards cesium. Those values are listed in Table 2 for all the materials studied in this publication.

Bulk compounds exhibit Cs sorption capacities in the same range than have already been found in past studies. ${ }^{27,50}$ The authors explain that the differences observed between all the Prussian blue analogues could be due to a difference in the sorption sites inside MHCF. The mechanism could be either a pure exchange with the alkaline ion present at the center of the lattice, or with transition metal elements present in the MHCF skeleton. In some cases, a mix of both mechanisms could also be responsible for Cs sorption inside MHCF. Those questions are still under investigation. In our case, only the $\mathrm{K}$ ion was present as a released ion in the aqueous solution after sorption experiments, arguing for a pure exchange between $\mathrm{K}$ and Cs. Another argument comes from the XRD data of the bulk ZnHCF after the sorption experiments in the presence of Cs (ESI - Fig. $\mathrm{S} 2 \dagger)$. It is noteworthy that this data exactly fits to the following compound $\mathrm{Cs}_{2} \mathrm{Zn}\left[\mathrm{Fe}(\mathrm{CN})_{6}\right]$ (pdf no. 00-038-0677).

The sorption performance differences for all of the bulk MHCFs are therefore probably due to the fact that in the case of CoHCF, for example, all K ions are not exchanged with Cs. Some authors explain that the affinity of HCF towards alkali ions depends on the intensity of the electrostatic field on the surface of the cation in the ferrocyanide. It is known that in the case of CoHCF, this value of field intensity leads to the inversion of the alkali metal affinity. ${ }^{58}$

This could explain why Cs sorption capacity obtained with CoHCF is lower than for the other MHCFs. Therefore, while bulk CoHCF exhibits a sorption capacity of about $110.4 \mathrm{mg} \mathrm{g}^{-1}$, bulk ZnHCF performance is strongly enhanced with a higher capacity of $340.5 \mathrm{mg} \mathrm{g}^{-1}$ and better selectivity towards Cs ions (Fig. 9). The presence of sodium in the aqueous solution containing Cs does not deeply affect the sorption performances of the bulk compounds. ZnHCF still presents the highest values of $Q_{\text {MAX }}$ and $K_{\mathrm{L}}$ quite close from those obtained without $\mathrm{Na}$ in the aqueous solution. The only noticeable difference concerns bulk CuHCF whose selectivity towards Cs decreases from $K_{\mathrm{L}}=16.7$ to $K_{\mathrm{L}}=1.5$ in the presence of Na. These results confirm the overall selectivity of bulk MHCF towards Cs even if more Na is present. In this case $\mathrm{Na}$ can be considered as a competitive ion to $\mathrm{Cs}$ because both ions are alkaline monovalent cations. However Cs sorption capacities remain nearly constant as well as selectivity except in the case of CuHCF.
The Cs sorption performance of the monoliths follows a similar trend to the bulk MHCF. This supports similar sorption mechanisms in both cases. In the case of the monoliths, as well as for the bulk compounds, Cs sorption is due to an ion exchange with $\mathrm{K}$ ions initially present in the MHCF particle lattices. Indeed, the comparison of Cs sorption capacities for the monoliths functionalised with different MHCF particles leads to a similar hierarchy of performances. These values are even rather identical to bulk HCF capacities with regard to the effective content of MHCF in the silica monolith (see Table 1). The Cs sorption selectivity is also decreased in the case of the monoliths with regard to the bulk compounds due to the fact that most of the solid is made of silica and only a light ratio of MHCF. While it is expected to note that $K_{\mathrm{L}}$ values are decreased for the monoliths, the disparities observed for all the kinds of monolith are not. For example, monoliths functionalised with CuHCF exhibit very small $K_{\mathrm{L}}$ values, ten times lower than for ZnHCF and CoHCF. This is in agreement with the results observed for bulk compounds in the presence of $\mathrm{Na}$ in the aqueous solution. This tends to confirm poorer selectivity of materials made with CuHCF. On the other hand, silica monoliths functionalised with ZnHCF still exhibit both high capacity and selectivity towards Cs. That is the reason why we selected this material for a final Cs sorption experiment in the presence of $\mathrm{Na}$ to assess whether competitive ions affect its performances. The results listed in Table 2 show that Cs sorption capacity remains constant while $K_{\mathrm{L}}$ is slightly decreased but still quite high. For example, while only $7.4 \%$ wt of $\mathrm{ZnHCF}$ is present in this silica monolith the $K_{\mathrm{L}}$ value is the same order than for pure bulk CuHCF.

Finally, Table 3 shows the comparison of Cs sorption capacities for various materials either from the literature or from this study. In all cases maximal sorption capacities are presented. It is noteworthy that the results obtained for "Monolith ZnHCF" are in the range of those previously shown for a wide field of hybrid nanomaterials. Moreover, the effect of the competitive ions such as $\mathrm{Na}$ is systematically insignificant if MHCF is used as the Cs sorbent. Table 3 also shows that most of the previous works were focused on post-functionalisation of mesoporous or non-porous nanoparticles support, but only a few deal with macroporous supports or one-pot functionalisation. Solely mesoporous supports allow a high level loading of MHCF particles but present limited interest in the frame of a continuous flow treatment. Therefore the silica monoliths 
Table 3 Comparison of the properties (type of sorbent, nature of the support, way of functionalisation, class of porosity, sorption capacity for Cs $Q_{\text {MAX }}$ and competition ions used for sorption experiments) and sorption capacities for relevant nanomaterials taken from bibliography and monoliths discussed in this study

\begin{tabular}{|c|c|c|c|c|c|c|}
\hline Sorbent & Support & Function & Porosity & $Q_{\text {MAX }}$ & $\begin{array}{l}\text { Competition } \\
\text { cation }\end{array}$ & Ref. \\
\hline CuHCF & SAMMS/MCM41 & Post & Meso- & $176.9 \mathrm{mg} \mathrm{g}^{-1}$ & $\mathrm{Na}$ & 51 \\
\hline NiHCF & Silica gel & Post & Macro- or meso- & $40.6 \mathrm{mg} \mathrm{g}^{-1}$ & $\mathrm{Na}$ & 52 \\
\hline Crown ether & Silica & Post & Meso- & $50.2 \mathrm{mg} \mathrm{g}^{-1}$ & $\mathrm{Na}, \mathrm{K}^{a}$ & 10 \\
\hline CuHCF & MCM41 & Post & Meso- & $3.7 \mathrm{mg} \mathrm{g}^{-1}$ & $\mathrm{Na}$ & 37 \\
\hline FeHCF & Graphene oxide/magnetite & Post & No & $55.5 \mathrm{mg} \mathrm{g}^{-1}$ & No & 53 \\
\hline NiHCF & Porous silica & Post & Meso & $225 \mathrm{mg} \mathrm{g}^{-1}$ & $\mathrm{Na}, \mathrm{K}$ & 54 \\
\hline CuHCF & SAMMS/MCM41 & Post & Meso- & $21.7 \mathrm{mg} \mathrm{g}^{-1}$ & Seawater & 55 \\
\hline ZnHCF & MCM41 & Post & Meso- & $103.1 \mathrm{mg} \mathrm{g}^{-1}$ & $\mathrm{Na}$ & 56 \\
\hline CoHCF, CuHCF, NiHCF & Latex & Post & No & $5.5 \mathrm{mg} \mathrm{g}^{-1}$ & $\mathrm{Na}$ & 21 \\
\hline $\mathrm{CoHCF}$ & SBA-15 & Post & Meso- & $17.3 \mathrm{mg} \mathrm{g}^{-1}$ & Seawater & 38 \\
\hline CoHCF & Sol-gel & One-pot & Meso- & $57.2 \mathrm{mg} \mathrm{g}^{-1}$ & $\mathrm{Na}$ & 57 \\
\hline CoHCF, CuHCF, ZnHCF & Silica monolith & One-pot & Meso- and macro- & $24.5 \mathrm{mg} \mathrm{g}^{-1}$ & $\mathrm{Na}$ & This study \\
\hline
\end{tabular}

${ }^{a}$ In this work, competition ions caused a decrease of the materials selectivity towards cesium ions.

discussed in this study are not only attractive for Cs sorption capacity but also for the hierarchical porosity and the way of functionalisation allowing the avoidance of the use of expensive silane based ligands such as aminopropyltriethoxysilane (APTES).

\section{Conclusions}

In summary this paper relates how to prepare silica monoliths designed for the selective uptake of radioactive cesium. This new method allows the combination of the advantages of a onepot procedure while maintaining calcination of the silica support. It is therefore possible to keep a high mechanical strength of the monoliths, while the functionalisation step allows the avoidance of the use of the non-green solvents generally employed for post-functionalisation treatment. This one-pot procedure allows the insertion of a quite high content ( $7.1 \% \mathrm{wt}$ ) of MHCF, a very effective cesium sorbent, inside the support macroporosity. The use of a high-internal phase emulsion template allows the design of a monolithic support with hierarchical porosity. Therefore, monolith mesoporosity ensures a high exchange surface during Cs sorption experiments.

The sorption results show that materials prepared with ZnHCF exhibit better performances with regard to CuHCF and CoHCF. The sorption capacity reaches $24.5 \mathrm{mg} \mathrm{g}^{-1}$ with a high selectivity even if competitive ions such as $\mathrm{Na}$ are present in the aqueous solution. The comparison with Cs sorption performed with bulk MHCFs also shows that the K-Cs exchange mechanisms are probably the same in both cases. This observation as well as the XRD patterns supports a safe one-pot procedure with regard to MHCF integrity.

At a time when selective materials, usable in a continuous process, are necessary for the treatment of aqueous outflows contaminated with radioactive Cs, especially in the case of decontamination operations in the Fukushima Daiichi nuclear plant, these materials bring a new solution, cheap and quite simple to achieve. Their chemical properties are relevant, not only with regard to Cs sorption capacity/selectivity but also from the insertion in waste conditioning matrices point of view. This is due to the fact that these monoliths are only made of silica and MHCF without additional organic compounds, such as grafting molecules for example, that could induce hydrogen release when exposed to irradiation coming from radionuclides. Indeed, past studies have already shown that silica $^{59}$ and $\mathrm{MHCF}^{60-62}$ were quite stable under gamma irradiation.

\section{Acknowledgements}

The authors would like to thank Xavier Le Goff and Franck Godiard for the TEM measurements, Alban Jonchère for the FTIR measurements, Bruno Corso for the XRD measurements and Anne Bleuzen for her help in the diffractogram interpretation, as well as Olivier Diat and Julien Cambedouzou for the SAXS measurements. This work has been funded by the French Agency for Research (grant RSNR-Demeterres, ANR-11-RSNR0005) and by the CEA/DEN project EDDEM. We therefore greatly thank the head manager of this project Frédéric Charton.

\section{Notes and references}

1 D. Zhihui, J. Mingchun and W. Xiaowei, J. Radioanal. Nucl. Chem., 2013, 298, 167-177.

2 A. Nilchi, R. Saberi, S. R. Garmarodi and A. Bagheri, Appl. Radiat. Isot., 2012, 70, 369-374.

3 A. Nilchi, H. Atashi, A. H. Javid and R. Saberi, Appl. Radiat. Isot., 2007, 65, 482-487.

4 A. Mardan, R. Ajaz, A. Mehmood, S. M. Raza and A. Ghaffar, Sep. Purif. Technol., 1999, 16, 147-158.

5 A. F. Seliman, Y. F. Lasheen, M. A. E. Youssief, M. M. Abo-Aly and F. A. Shehata, J. Radioanal. Nucl. Chem., 2014, 300, 969979.

6 S. A. Khan, J. Radioanal. Nucl. Chem., 2003, 258, 3-6. 
7 K. Iijima, T. Tomura and Y. Shoji, Appl. Clay Sci., 2010, 49, 262-268.

8 B. Filipowicz, M. Pruszynski, S. Krajewski and A. Bilewicz, J. Radioanal. Nucl. Chem., 2014, 301, 889-895.

9 H. Tel, Y. Altas, F. Gur and A. Ugur, Radiochim. Acta, 2010, 98, 215-219.

10 M. R. Awual, S. Suzuki, T. Taguchi, H. Shiwaku, Y. Okamoto and T. Yaita, Chem. Eng. J., 2014, 242, 127-135.

11 Y. Wu, S. Y. Kim, D. Tozawa, T. Ito, T. Tada, K. Hitomi, E. Kuraoka, H. Yamazaki and K. Ishii, J. Radioanal. Nucl. Chem., 2012, 293, 13-20.

12 E. H. Borai, R. Harjula, L. Malinen and A. Paajanen, J. Hazard. Mater., 2009, 172, 416-422.

13 D. Sarma, C. D. Malliakas, K. S. Subrahmanyam, S. M. Islama and M. G. Kanatzidis, Chem. Sci., 2016, 7, 1121-1132.

14 J. L. Mertz, Z. H. Fard, C. D. Malliakas, M. J. Manos and M. G. Kanatzidis, Chem. Mater., 2013, 25, 2116-2127.

15 N. Ding and M. G. Kanatzidis, Nat. Chem., 2010, 2, 187-191.

16 M. J. Manos and M. G. Kanatzidis, J. Am. Chem. Soc., 2009, 131, 6599-6607.

17 H. Zhang, X. Zhao, J. Wei and F. Li, Chem. Eng. J., 2015, 275, 262-270.

18 J. Sung-Chan, H. Sang-Bum, Y. Hee-Man, L. Kune-Woo, M. Jei-Kwon, S. Bum-Kyoung, H. Yun Suk and R. Changhyun, Nanomaterials, 2014, 4, 894-901.

19 J. Li, W. Shen, B. Kang, S. Chang and Y. Dai, Micro Nano Lett., 2014, 9, 825-828.

20 H. Fei, Z. Guang-Hui and G. Ping, J. Radioanal. Nucl. Chem., 2013, 295, 369-377.

21 V. Avramenko, S. Bratskaya, V. Zheleznov, I. Sheveleva, O. Voitenko and V. Sergienko, J. Hazard. Mater., 2011, 186, 1343-1350.

22 B. Li, J. Liao, J. Wu, D. Zhang, J. Zhao, Y. Yang, Q. Cheng, Y. Feng and N. Liu, Nucl. Sci. Tech., 2008, 19, 88-92.

23 C. Loos-Neskovic, S. Ayrault, V. Badillo, B. Jimenez, E. Garnier, M. Fedoroff, D. J. Jones and B. Merinov, J. Solid State Chem., 2004, 177, 1817-1828.

24 R. D. Ambashta, P. K. Wattal, S. Singh and D. Bahadur, J. Magn. Magn. Mater., 2003, 267, 335-340.

25 R. Harjula, J. Lehto, A. Paajanen, L. Brodkin and E. Tusa, Nucl. Sci. Eng., 2001, 137, 206-214.

26 S. Ayrault, B. Jimenez, E. Garnier, M. Fedoroff, D. J. Jones and C. Loos-Neskovic, J. Solid State Chem., 1998, 141, 475485.

27 P. A. Haas, Sep. Sci. Technol., 1993, 28, 2479-2506.

28 C. Loos-Neskovic, C. Vidal-Madjar, B. Jimenez, A. Pantazaki, V. Federici, A. Tamburini, M. Fedoroff and E. Persidou, Radiochim. Acta, 1999, 85, 143-148.

29 R. Ishihara, K. Fujiwara, T. Harayama, Y. Okamura, S. Uchiyama, M. Sugiyama, T.-A. Someya, W. Amakai, S. Umino, T. Ono, A. Nide, Y. Hirayama, T. Baba, T. Kojima, D. Umeno, K. Saito, S. Asai and T. Sugo, J. Nucl. Sci. Technol., 2011, 48, 1281-1284.

30 A. Takahashi, A. Kitajima, D. Parajuli, Y. Hakuta, H. Tanaka, S.-i. Ohkoshi and T. Kawamoto, Chem. Eng. Res. Des., 2016, 109, 513-518.
31 K.-M. Lee, T. Kawamoto, K. Minami, A. Takahashi, D. Parajuli, G. Kido, K. Yoshino and H. Tanaka, RSC Adv., 2016, 6, 16234-16238.

32 N. Shimamoto, S. Ohkoshi, O. Sato and K. Hashimoto, Inorg. Chem., 2002, 41, 678-684.

33 C. Loosneskovic, M. Fedoroff and E. Garnier, Talanta, 1989, 36, 749-759.

34 C. Loosneskovic, M. Fedoroff, E. Garnier and P. Gravereau, Talanta, 1984, 31, 1133-1147.

35 J. Causse, A. Tokarev, J. Ravaux, M. Moloney, Y. Barre and A. Grandjean, J. Mater. Chem. A, 2014, 2, 9461-9464.

36 A. Grandjean, C. Delchet, J. Causse, Y. Barré, Y. Guari and J. Larionova, J. Radioanal. Nucl. Chem., 2015, 1-10, DOI: 10.1007/s10967-015-4098-1.

37 R. Turgis, G. Arrachart, C. Delchet, C. Rey, Y. Barre, S. PelletRostaing, Y. Guari, J. Larionova and A. Grandjean, Chem. Mater., 2013, 25, 4447-4453.

38 C. Delchet, A. Tokarev, X. Dumail, G. Toquer, Y. Barre, Y. Guari, C. Guerin, J. Larionova and A. Grandjean, RSC Adv., 2012, 2, 5707-5716.

39 K. Kanamori, H. Yonezawa, K. Nakanishi, K. Hirao and H. Jinnai, J. Sep. Sci., 2004, 27, 874-886.

40 K. Nakanishi and N. Soga, J. Non-Cryst. Solids, 1992, 139, 113.

41 N. Brun, S. R. S. Prabaharan, M. Morcrette, C. Sanchez, G. Pecastaings, A. Derre, A. Soum, H. Deleuze, M. Birot and R. Backov, Adv. Funct. Mater., 2009, 19, 3136-3145.

42 B. P. Binks, Adv. Mater., 2002, 14, 1824-1827.

43 G. Fornasieri, M. Aouadi, E. Delahaye, P. Beaunier, D. Durand, E. Rivière, P.-A. Albouy, F. Brisset and A. Bleuzen, Materials, 2012, 5, 385-403.

44 P. Gravereau, E. Garnier and A. Hardy, Acta Crystallogr., Sect. B: Struct. Crystallogr. Cryst. Chem., 1979, 35, 2843-2848.

45 V. K. Aswal, P. S. Goyal, J. Kohlbrecher and P. Bahadur, Chem. Phys. Lett., 2001, 349, 458-462.

46 E. Florin, R. Kjellander and J. C. Eriksson, J. Chem. Soc., Faraday Trans. 1, 1984, 80, 2889-2910.

47 G. Fornasieri, M. Aouadi, P. Durand, P. Beaunier, E. Riviere and A. Bleuzen, Chem. Commun., 2010, 46, 8061-8063.

48 D. Y. Zhao, J. L. Feng, Q. S. Huo, N. Melosh, G. H. Fredrickson, B. F. Chmelka and G. D. Stucky, Science, 1998, 279, 548-552.

49 D. Y. Zhao, Q. S. Huo, J. L. Feng, B. F. Chmelka and G. D. Stucky, J. Am. Chem. Soc., 1998, 120, 6024-6036.

50 C. Loosneskovic and M. Fedoroff, Solvent Extr. Ion Exch., 1989, 7, 131-158.

51 Y. H. Lin, G. E. Fryxell, H. Wu and M. Engelhard, Environ. Sci. Technol., 2001, 35, 3962-3966.

52 H. Mimura, M. Kimura, K. Akiba and Y. Onodera, Solvent Extr. Ion Exch., 1999, 17, 403-417.

53 H. Yang, L. Sun, J. Zhai, H. Li, Y. Zhao and H. Yu, J. Mater. Chem. A, 2014, 2, 326-332.

54 C.-Y. Chang, L.-K. Chau, W.-P. Hu, C.-Y. Wang and J.-H. Liao, Microporous Mesoporous Mater., 2008, 109, 505-512.

55 T. Sangvanich, V. Sukwarotwat, R. J. Wiacek, R. M. Grudzien, G. E. Fryxell, R. S. Addleman, C. Timchalk and W. Yantasee, J. Hazard. Mater., 2010, 182, 225-231. 
56 S. Vashnia, H. Tavakoli, R. Cheraghali and H. Sepehrian, Desalin. Water Treat., 2015, 55, 1220-1228.

57 D. V. Ca and J. A. Cox, Microchim. Acta, 2004, 147, 31-37.

58 V. Pekárek and V. Veselý, Talanta, 1972, 19, 1245-1283.

59 D. Dondi, A. Buttafava, A. Zeffiro, S. Bracco, P. Sozzani and A. Faucitano, J. Phys. Chem. A, 2013, 117, 3304-3318.
60 M. Arisaka, M. Watanabe, M. Ishizaki, M. Kurihara, R. Chen and H. Tanaka, J. Radioanal. Nucl. Chem., 2015, 303, 15431547.

61 A. Nilchi, B. Malek, M. G. Maragheh and A. Khanchi, Radiat. Phys. Chem., 2003, 68, 837-842.

62 J. Lehto and L. Szirtes, Radiat. Phys. Chem., 1994, 43, 261264. 